\title{
BMJ Open Cost-effectiveness analysis of a community paramedicine programme for low-income seniors living in subsidised housing: the community paramedicine at clinic programme (CP@ clinic)
}

\author{
Gina Agarwal (1) ,1,2 Melissa Pirrie (1) , ${ }^{1}$ Ricardo Angeles, ${ }^{1}$ Francine Marzanek, ${ }^{1}$ \\ Lehana Thabane, ${ }^{2,3}$ Daria O'Reilly ${ }^{2,4}$
}

To cite: Agarwal G, Pirrie M, Angeles R, et al. Costeffectiveness analysis of a community paramedicine programme for lowincome seniors living in subsidised housing: the community paramedicine at clinic programme (CP@clinic). BMJ Open 2020;10:e037386. doi:10.1136/ bmjopen-2020-037386

- Prepublication history and additional materials for this paper is available online. To view these files, please visit the journal online (http://dx.doi. org/10.1136/bmjopen-2020037386).

Received 30 January 2020 Revised 01 September 2020 Accepted 22 September 2020

Check for updates

(C) Author(s) (or their employer(s)) 2020. Re-use permitted under CC BY-NC. No commercial re-use. See rights and permissions. Published by BMJ.

For numbered affiliations see end of article.

Correspondence to

Dr Gina Agarwal;

gina.agarwal@gmail.com

\section{ABSTRACT}

Objectives To evaluate the cost-effectiveness of the Community Paramedicine at Clinic (CP@clinic) programme compared with usual care in seniors residing in subsidised housing.

Design A cost-utility analysis was conducted within a large pragmatic cluster randomised controlled trial (RCT). Subsidised housing buildings were matched by sociodemographics and location (rural/urban), and allocated to intervention (CP@clinic for 1 year) or control (usual care) via computer-assisted paired randomisation. Setting Thirty-two subsidised seniors' housing buildings in Ontario.

Participants Building residents 55 years and older. Intervention CP@clinic is a weekly community paramedic-led, chronic disease prevention and health promotion programme in the building common areas. CP@ clinic is free to residents and includes risk assessments, referrals to resources, and reports back to family physicians.

Outcome measures Quality-adjusted life years (QALYs) gained, measured with EQ-5D-3L. QALYs were estimated using area-under-the curve over the 1-year intervention, controlling for preintervention utility scores and building pairings. Programme cost data were collected before and during implementation. Costs associated with emergency medical services (EMS) use were estimated. An incremental cost effectiveness ratio (ICER) based on incremental costs and health outcomes between groups was calculated. Probabilistic sensitivity analysis using bootstrapping was performed.

Results The RCT included 1461 residents; 146 and 125 seniors completed the EQ-5D-3L in intervention and control buildings, respectively. There was a significant adjusted mean QALY gain of 0.03 (95\% Cl 0.01 to 0.05$)$ for the intervention group. Total programme cost for implementing in five communities was \$C128462 and the reduction in EMS calls avoided an estimated \$C256583. The ICER was \$C2933/QALY (bootstrapped mean ICER with Fieller's 95\% Cl was $\$ 4850$ (\$2246 to \$12396)) but could be even more cost effective after accounting for the EMS call reduction.
Strengths and limitations of this study

- The study is an economic evaluation of a community paramedicine (CP) programme.

- CP programmes are infrequently evaluated from a health economic perspective.

- This study adopts the perspective of the paramedic service that might implement such a programme.

- This evaluation did not include long-term implications of the programme and therefore may have underestimated its economic value.

- A uniform cost was applied for emergency medical service use despite potential differences due to service or type of call, therefore slight variations in cost remain unaccounted.

Conclusion The CP@clinic ICER was well below the commonly used Canadian cost-utility threshold of \$C50 000. CP@clinic scale-up across subsidised housing is feasible and could result in better health-related qualityof-life and reduced EMS use in low-income seniors. Trial registration number Clinicaltrials.gov, NCT02152891.

\section{INTRODUCTION}

Community paramedicine (CP) is an emerging field that is actively expanding across Canada. Community paramedics are deployed in non-traditional, non-acute response settings, which can involve health promotion and disease prevention activities. ${ }^{1}$ This new paramedicine role has already demonstrated having a positive impact on the quality of life and health of vulnerable populations, ${ }^{23}$ while also reducing utilisation of emergency medical services (EMS) ${ }^{23}$ In addition, there are potential benefits to the health and well-being of paramedics who take on CP 
roles. ${ }^{4-6}$ Though CP models are emerging widely, evaluation of these programmes and activities is rare and those that do exist lack rigour. ${ }^{1}$ Evaluation of CP programmes should include economic evaluations in order to drive and inform policy change in health authorities. Where these economic evaluations can take account of staffing models, such as modified or non-modified/regular staff, it is even more applicable to healthcare planning.

Though some CP programmes from differing contexts have been evaluated for cost-effectiveness, a recent review for Alberta Health Services concluded that the costeffectiveness of the CP trials included in their study was not readily generalisable to other settings due to differences in programme models. ${ }^{7}$ The programmes that had a cost-effectiveness evaluation constituted one involving an on-site nurse practitioner-paramedic collaboration and off-site family physician for patients over 40 years of age with chronic disease, and another with a paramedic practitioner for patients over 60 years of age. A recent study conducted in Renfrew County, Ontario, performed an economic evaluation of a home visit programme model (ageing at home) and was able to demonstrate an incremental cost per quality-adjusted life year (QALY). ${ }^{8}$ However, no studies have evaluated the cost-effectiveness of a wellness or clinic style community model of CP.

The $\mathrm{CP}$ at Clinic (CP@clinic) programme has been evaluated in the format of a rigorous randomised controlled trial (RCT), in which the sensitivity analysis found CP@clinic to have positive effects on the reduction of EMS calls from implementation sites, with a reduction of -0.88 calls $/$ month $/ 100$ apartment units in Hamilton, and a reduction of -0.90 calls $/$ month $/ 100$ apartment units in five communities. ${ }^{2}{ }^{3}$ We sought to evaluate the cost-effectiveness of the CP@clinic programme compared with usual care for low-income seniors living in subsidised (social) housing using a cost-utility analysis. The perspective of the paramedic service was chosen since it is the implementer of such community programmes, and can receive funding from multiple sources, both ministry and public payer, depending on its geographic location. Therefore, the paramedic service perspective is the most transferable, and they would require this type of information to determine future implementation.

\section{METHODS}

\section{Design and setting}

This cost-utility analysis (with multiple sensitivity analyses) was conducted from the perspective of paramedic services within the context of a large pragmatic cluster RCT in 2015/2016 for which the protocol ${ }^{9}$ and results ${ }^{3}$ have been published elsewhere. The 1-year RCT evaluated the CP@clinic programme in subsidised housing for seniors (aged 55 and older) in five communities across Ontario, Canada. The cost-utility analysis was conducted alongside the trial, using quality-of-life measures that could be translated into comparable outcomes. Twenty-six subsidised seniors' buildings, matched by sociodemographics and location (rural and urban, Ontario), were allocated to intervention (CP@clinic for 1 year) or control (usual care) via computer-assisted paired randomisation. Housing organisations provided building level information which was used in the matching process: proportion of 'older aged' residents, number of units in the building, number of 911 calls per month per 100 units (baseline) and presence of building-level wellness programming. Inclusion criteria were that each building required more than $60 \%$ of residents aged 55 years and older, more than 50 residential units, a unique postal code, and had at least one building of similar size and demographic to form a matched pair. There were no exclusion criteria.

\section{Patient and public involvement}

The broader RCT, through which these data were collected, was first piloted in a single location where building residents (participants) and paramedics had multiple opportunities to shape the future RCT study design and implementation, through comments on the programme. Paramedics provided expert advice on the intervention locations (buildings), timing and session length in social housing. They also advised on their opinion regarding the best method for providing immediate reports to the participants (eg, printing on-site was not feasible) and sending reports to family doctors. In addition, paramedics informed some of the process metrics collected and disseminated in the study's regular stakeholder reports. Pilot study participants provided input on the best location within the housing building for the sessions, session timing, paramedic consistency (ie, having the same paramedic each week) and participant resources (eg, participant card for tracking their goals and measurements). Results were not disseminated to patients, other than each individuals' assessment summary which was provided to them after each session.

\section{Intervention}

Standardised weekly CP@clinic sessions were delivered at buildings by community paramedics. A full description of the CP@clinic programme is available elsewhere. ${ }^{2}$ Risk assessment, disease prevention and health promotion sessions were led by community paramedics, using validated tools focusing on cardiovascular, diabetes and fall risk. Sessions were open to all building residents and one-on-one and drop-in, taking place in common areas of intervention buildings. After informed consent was taken, paramedics entered data directly into the CP@clinic database, which generated decision support advice. Attendees were counselled on specific lifestyle changes and accessible community resources or relevance Attendees were given a session card outlining their modifiable risk factors and resources that had been discussed. Session summaries were faxed to family physicians, with patient consent. Control buildings received usual care, or services that residents may access by visiting their family physician and ongoing services in their building by local community agencies. 


\section{Data collection}

All costs presented are in Canadian dollars for the 2016 year and represent the costs to the paramedic service implementing $\mathrm{CP} @$ clinic (programme and staffing costs).

\section{Quality of life}

Data were collected on quality-of-life from intervention and control building residents before (between October 2014 and December 2015) and after the programme (between December 2015 and December 2016). The data collection timing reflected the staggered nature of the RCT starts dates in each site, though at least 12 months was allowed between the before and after surveying. We used the EuroQol Quality of Life Measurement Tool, EQ-5D 3L, by permission. ${ }^{10}$ Participants, who were building residents 55 years and older, were invited to complete the survey through invitation posters that were displayed throughout the building, and flyers that were handed out to residents, describing the day and time that the research team would be present to administer the questionnaires. After obtaining informed written consent, data collection was performed by trained research assistants, on paper, due to low educational levels and poor health literacy of participants. ${ }^{11}$ The research assistant read each question to the participant, including the answer categories and prompts, and noted the participant's responses. A consecutive sampling method was used, due to the difficulty of surveying in this vulnerable population. ${ }^{11}$ On completion, the participants were provided with a local grocery gift card worth $\$ 10$.

\section{Programme costs}

In all communities that took part in the CP@clinic RCT it was found that the local housing authority routinely did not charge for space when other publicly funded or nonprofit organisations were providing health and wellness programming to residents. It is not within the mandate of regional or municipal housing organisations to provide health-related services, ${ }^{12}$ but they recognise the value of these types of programmes for residents, so they welcomed CP@clinic using the space in-kind. Direct programme costs of running $\mathrm{CP} @$ clinic included the vehicle to transport the community paramedics between their base and each of the intervention buildings, technology-related costs (software, information technology support, database administration and YubiKey) and session equipment (laptop, weighing scale, tape measure, blood glucose measurement items, WatchBP Office blood pressure monitoring device and a carry bag).

\section{Staffing costs}

Paramedic services are responsible for all of these costs. These included salaries, materials for session implementation and technology-related costs. Where possible, costs were obtained from the source from which the service, object or goods were obtained. Detailed records were kept of all materials required for the implementation of the programme. These records were validated with community paramedic supervisors. Staffing hours and salary levels were also verified with paramedic services. Paramedic salary hourly costs were obtained from paramedic services implementing $\mathrm{CP} @$ clinic and where unknown, the highest salary from other services was used. The combined hourly cost of supervision and administration within the paramedic service to oversee the community paramedics was estimated at $200 \%$ of paramedic hourly salary with benefits based on information provided by the services. Paramedic vehicle and vehicle-related costs (ie, mileage to cover maintenance and fuel) were also obtained from the paramedic services directly. Since the paramedic services implementing CP@clinic had different paramedic salary rates, staffing models (dedicated community paramedics vs paramedics on modified duty), and vehicle-related costs, the total actual costs for all five RCT sites together were used to evaluate costeffectiveness. Also, in order to inform paramedic services considering implementing CP@clinic in the future, the costs for each staffing model observed during the RCT have been presented as a sensitivity analysis with three potential staffing models later. Note that staff placed on modified duties are those who are unable to do regular paramedic duties because of temporary physical/mental health conditions.

1. Model 1 (minimum): two paramedics staffing CP@ clinic, both on 'modified' duties, therefore not requiring additional salary costing; 1 hour per week of administrative time; and other staffing (eg, database management) provided in-kind or funded by external sources.

2. Model 2 (moderate): two paramedics staffing CP@ clinic, but one paid as a community paramedic, and one on modified duties; 1.5 hours per week of administrative time, and the cost of other staffing split 50/50 between the paramedic service and external/in-kind funding.

3. Model 3 (maximum): two paramedics staffing CP@ clinic, both paid as community paramedics; 2 hours per week of administrative time, and the full cost of other staffing being paid for by the paramedic service. Since the paramedic service perspective has been taken, the healthcare costs examined in this paper do not go beyond the EMS call (eg, hospital admissions, duration of stay, specialist visits). Data on the number of EMS calls avoided were taken from the RCT results (see table 1), which found that the intervention buildings had 10.8 fewer calls per 100 apartment units postintervention, compared with control buildings. The costs (in Canadian dollars) estimated for potential EMS call offset were obtained from Canadian literature in 2017 where we found $\$ 499 /$ call to be a minimum cost, $\$ 1626 /$ call to be a moderate cost and $\$ 2254 /$ call to be the maximum cost. ${ }^{13}$ Inflation according to the Consumer Price Index for Healthcare, ${ }^{14}$ was not required since the 1-year intervention was in 2015/2016. The base case cost-utility analysis was conducted without any cost offset from the avoided EMS calls and then a sensitivity analysis was conducted 
Table 1 Difference in EMS call rates for intervention and control buildings (main trial results)

\begin{tabular}{lccc}
\hline & $\begin{array}{l}\text { Intervention } \\
\text { buildings mean (SD) }\end{array}$ & $\begin{array}{l}\text { Control buildings } \\
\text { mean (SD) }\end{array}$ & $\begin{array}{l}\text { Mean difference } \\
\text { (95\% CI) }\end{array}$ \\
\hline Baseline: unadjusted monthly EMS calls per 100 units & $4.13(2.79)$ & $4.60(2.80)$ & $-0.47(-1.12$ to 0.18$)$ \\
\hline After 1 year: unadjusted monthly EMS calls per 100 units & $3.67(2.75)$ & $4.79(2.93)$ & $-1.12(-1.78$ to 0.46$)$ \\
Unadjusted: monthly mean difference & $-0.47(3.83)$ & $0.19(3.57)$ & $-0.65(-1.51$ to 0.20$)$ \\
\hline Adjusted:* monthly mean difference & - & - & $-0.90(-1.54$ to -0.26$) \dagger$
\end{tabular}

Expected annual decrease in 911 calls: 10.8 calls/100 apartment units/year.

$\mathrm{n}=26$ buildings ( 13 pairs of intervention and control buildings).

${ }^{*}$ Adjusted for building pairing and preintervention baseline. $\mathrm{tp}<0.006$.

using a range of potential cost offsets depending on the value assigned to the average EMS call.

\section{Outcomes}

The main outcome was QALY gained (change from baseline) in the intervention buildings compared with the control buildings, over the 1-year intervention period. This was used because of the difference in the utilities of participants at baseline. ${ }^{15}$ The cost-effectiveness outcomes were analysed and presented as incremental cost-effectiveness ratios (ICERs) of the intervention (CP@ clinic) versus control (usual care). Cost-effectiveness, in the form of a cost-utility analysis, was evaluated based on the cost of implementing and maintaining the CP programme and QALYs as the measure of effectiveness; sensitivity analyses also included EMS calls avoided in the ICER calculation. ICERs were presented where appropriate (when the intervention was not dominant/dominated). The time horizon of the analysis was 12 months, therefore discounting techniques were not used.

\section{Analysis}

The QALYs were estimated by assuming linear change and calculating area-under-the-curve, for the 1-year programme period (utility scores at baseline and 1-year postintervention were summed and then divided by two). The raw EQ-5D-3L survey responses were treated as fivedigit vectors (eg, 13415) and transformed into index scores using the previously validated Canadian EQ-5D-3L value sets. ${ }^{16}$ QALYs were regression adjusted for preintervention utility scores and building pairing. Missing QALYs were calculated using multiple imputation techniques (iterative Markov chain Monte Carlo method). Age, education, presence of chronic diseases (hypertension, heart disease, diabetes, high cholesterol, previous stroke), gender, living arrangement (living alone, marital status), baseline EQ5D measures (by individual domains) and baseline utility were used to impute for the missing utility values.

Cost of the programme per resident was calculated by dividing the total programme cost (summation of all programme expenses) divided by the number of units in the intervention buildings. This provided a conservative estimate of the cost per resident since over $90 \%$ of units only had one resident ${ }^{3}$; as the number of residents per unit increases, the cost per resident decreases, therefore assuming one resident per unit is the most conservative approach to estimating the cost per resident with fluctuating building resident numbers. The incremental cost per QALY was the ratio of the difference in cost of the CP@ clinic per building resident compared with the control group ( $\$ 0$ was assumed because there was no programme added) divided by the difference in mean QALY gained in the intervention group compared with the control group. In addition, we conducted Bootstrap probabilistic sensitivity analysis (PSA) using 1000 bootstrap samples of the complete case dataset of QALYs (controlling for baseline utility scores and pairing using regression) to determine the uncertainty around the ICER. We created a cost-effectiveness acceptability (CEA) curve based on the PSA analysis to show the probability of the programme being cost-effective based on the willingness to pay. Also, potential net programme costs were calculated based on the range of costs that could be assigned to each EMS call avoided.

We used the ICER threshold of \$C50000 per QALY, which has been suggested as a conservative lower boundary for a willingness to pay threshold. ${ }^{17}$

The programme cost per EMS call avoided was the ratio of total programme cost over the total number of EMS calls avoided. Finally, the potential net cost for a future site wanting to implement the $\mathrm{CP} @$ clinic programme in two buildings and in four buildings was calculated for each of the three different staff costing scenarios and each of the three cost-offset scenarios.

\section{RESULTS}

\section{Main trial results}

As published previously, the CP@clinic RCT demonstrated significantly reduced EMS calls after 1 year of implementation when adjusted for the study design (ie, building pairing) and baseline calls in the sensitivity analysis. ${ }^{3}$ Comparing intervention and control buildings, there was an adjusted mean monthly difference of -0.90 calls per 100 apartment units per month $(95 \% \mathrm{CI}-1.54$ to $-0.26)$, which translates to an estimated 10.8 fewer EMS 


\begin{tabular}{|c|c|c|c|}
\hline & \multicolumn{3}{|c|}{$\begin{array}{l}\text { Intervention building residents vs control building } \\
\text { residents }\end{array}$} \\
\hline & $\begin{array}{l}\text { Intervention } \\
\text { mean (SD) }\end{array}$ & $\begin{array}{l}\text { Control mean } \\
\text { (SD) }\end{array}$ & $\begin{array}{l}\text { Mean difference } \\
(95 \% \mathrm{Cl})\end{array}$ \\
\hline Main trial results with multiple imputation (intention-to-treat) & $n=358$ & $n=320$ & \\
\hline $\begin{array}{l}\text { Adjusted* QALY: QALY, regression adjusted for baseline utility score and } \\
\text { building pairing }\end{array}$ & $0.72(0.11)$ & $0.69(0.20)$ & $0.03 \dagger(0.01$ to 0.05$)$ \\
\hline $\begin{array}{l}\text { Adjusted* QALY: QALY, regression adjusted for baseline utility score and } \\
\text { building pairing }\end{array}$ & $0.72(0.09)$ & $0.69(0.09)$ & $0.03 \dagger(0.01$ to 0.05$)$ \\
\hline $\begin{array}{l}\text { Bootstrap probabilistic sensitivity analysis: adjusted* QALY (QALY, } \\
\text { regression adjusted for baseline utility score and building pairing) }\end{array}$ & $0.74(0.09)$ & $0.71(0.09)$ & $0.03 \dagger(0.01$ to 0.05$)$ \\
\hline
\end{tabular}

*Intervention and control EQ-5D index scores were found to be significantly different at baseline, despite randomisation, therefore baseline differences were accounted for by adjustment using regression. $\dagger p<0.05$.

QALY, quality-adjusted life year.

calls per 100 apartment units per year (see table 1). Since the intervention buildings had 1461 units, it can be estimated that 157.8 EMS calls were avoided during the intervention period.

In addition, the $\mathrm{CP} @$ clinic intervention had a positive effect on resident health-related quality of life in the intervention buildings, compared with the control buildings (see table 2); this is a building-level result that includes individuals from the intervention buildings, regardless of whether or not they opted to attend the programme sessions. A total of 358 residents from intervention buildings and 320 residents from control buildings participated in the survey prior to the start of the intervention (preintervention). At 1-year postintervention, 196 residents from the intervention buildings and 125 residents from the control buildings completed the survey again due to some having moved, died or being lost to follow-up (see figure 1). Resident demographics per site are shown in online supplemental table 1. Multiple imputation was

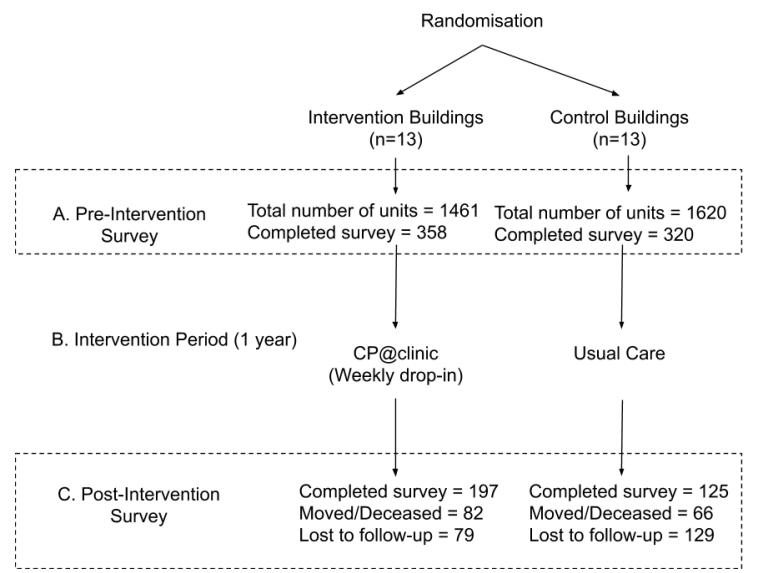

Figure 1 CP@clinic study design and data collection flow diagram. CP@clinic, Community Paramedicine at Clinic programme. used to account for the missing data in the sensitivity analysis.

At the end of the 1-year intervention, when adjusting for baseline differences in the EQ-5D index score between the intervention and control buildings and for building pairing using regression, there was a significant adjusted mean 0.03 QALY change per person $(95 \% \mathrm{CI}$ 0.01 to 0.05$)$.

\section{Programme costs}

Direct costs

The direct programme cost of CP@clinic per community was $\$ 12962$, and the overall direct programme cost for the five communities in the RCT was $\$ 64810$, excluding staffing. See table 3 for the list of costs per item and source.

\section{Staffing costs}

Each site had different staffing arrangements during the RCT, such as rate of pay, number of buildings receiving the intervention, and number of paramedics on modified duties staffing the wellness clinics (see online supplemental table 2). Therefore, the actual staffing costs for each of the five sites ranged from $\$ 5499$ to $\$ 25165$, for a total staffing cost of $\$ 63652$ for the RCT implementation year (see table 4 ). In addition, a sensitivity analysis of potential staffing costs based on assumptions described in the methods. If a future site wanted to implement the programme in two buildings, the estimated staffing costs would be $\$ 5499$ using the minimum assumptions, $\$ 31745$ using the moderate assumptions and $\$ 57990$ using the maximum assumptions (see table 4). Furthermore, if a future site wanted to implement the programme in four buildings, the estimated staffing costs would be $\$ 5499$ using the minimum assumptions, \$53741 using the moderate assumptions and \$101982 using the maximum assumptions. 
Table 3 Direct programme costs in Canadian dollars (excluding staffing)

\begin{tabular}{|c|c|c|}
\hline Item & Source & $\begin{array}{l}\text { Cost per site } \\
\text { (\$C in 2016) }\end{array}$ \\
\hline Space & $\begin{array}{l}\text { Housing authority of } \\
\text { each community }\end{array}$ & In-kind \\
\hline $\begin{array}{l}\text { Vehicle incl. fuel and } \\
\text { maintenance }\end{array}$ & $\begin{array}{l}\text { Paramedic service of } \\
\text { each community }\end{array}$ & 10000 \\
\hline $\begin{array}{l}\text { Information } \\
\text { technology supports } \\
\text { and overheads }\end{array}$ & $\begin{array}{l}\text { McMaster University, } \\
\text { DFM IT }\end{array}$ & 500 \\
\hline Database software & $\begin{array}{l}\text { McMaster University, } \\
\text { DFM IT }\end{array}$ & 235 \\
\hline YubiKey & $\begin{array}{l}\text { McMaster University, } \\
\text { DFM IT }\end{array}$ & 53 \\
\hline $\begin{array}{l}\text { Printing and materials } \\
\text { (eg, posters, flyers, } \\
\text { BP record card) }\end{array}$ & $\begin{array}{l}\text { McMaster University } \\
\text { Media Services }\end{array}$ & 253 \\
\hline \multicolumn{3}{|l|}{ Session equipment } \\
\hline Laptop & $\begin{array}{l}\text { McMaster University, } \\
\text { DFM IT }\end{array}$ & 726 \\
\hline Weighing scale & $\begin{array}{l}\text { Medical supply } \\
\text { vendor }\end{array}$ & 240 \\
\hline Tape measure & $\begin{array}{l}\text { Medical supply } \\
\text { vendor }\end{array}$ & 5 \\
\hline $\begin{array}{l}\text { BP machine } \\
\text { (WatchBP Office) }\end{array}$ & $\begin{array}{l}\text { Medical supply } \\
\text { vendor }\end{array}$ & 750 \\
\hline $\begin{array}{l}\text { Glucometer, } \\
\text { lancets, swabs, } \\
\text { bandages }\end{array}$ & $\begin{array}{l}\text { Paramedic service of } \\
\text { each community }\end{array}$ & 150 \\
\hline Carry bag & Office supply vendor & 50 \\
\hline \multicolumn{2}{|c|}{ Direct programme costs per community } & 12962 \\
\hline \multicolumn{2}{|c|}{$\begin{array}{l}\text { Total direct programme costs for all five RCT } \\
\text { study sites }\end{array}$} & 64810 \\
\hline
\end{tabular}

BP, blood pressure; DFM IT, Department of Family Medicine Information Technology team; RCT, randomised controlled trial.

\section{Total programme costs}

Taking the direct programme costs $(\$ 64810)$ together with the staffing costs (\$63652), the actual cost of running the intervention in all five RCT sites for 1 year was $\$ 128462$. Under the different staffing assumptions, the total programme costs for one community planning to implement CP@clinic in the future would be expected to range from $\$ 18461$ to $\$ 70952$ for two buildings and from $\$ 18461$ to $\$ 114944$ for four buildings.

Given that there were 1461 apartment units in the intervention buildings and using a conservative estimate of one resident per apartment unit (more than $90 \%$ of the building residents live alone ${ }^{3}$ ), the total programme cost per resident was $\$ 88$ for this RCT. For each site, the programme cost per resident ranged from $\$ 35$ to $\$ 292$. This calculation assumed that all residents had the potential to attend the programme, whether they did or not, as per our other costings. In addition, the total programme cost per EMS call avoided was $\$ 814$.

\section{Cost-utility main analysis}

The CP@clinic RCT found a gain of 0.03 QALY per intervention building resident (see table 2). Therefore, the programme cost per QALY gained of the CP@clinic intervention was $\$ 2933$ (see table 5). This value was well below the $\$ 50000$ willingness to pay threshold commonly suggested for health intervention cost-effectiveness.

\section{PSA using bootstrapping}

After the bootstrapping analysis was performed, the $\mathrm{CP} @$ clinic RCT found a QALY gain of 0.03 per intervention building resident (see table 2). The mean ICER with Fieller's 95\% CI was $\$ 4850$ ( $\$ 2246$ to $\$ 12396$ ). The CEA curve is presented in figure 2 with a willingness-to-pay threshold of $\$ 50000$ demonstrating that $100 \%$ acceptability was achieved well below this threshold.

\section{Cost-utility analysis with additional cost offsets}

The base case cost-utility analysis reported earlier did not include any cost offsets. From the perspective of a paramedic service, the potential cost offset due to reduced EMS calls observed in the RCT (main trial results) could vary depending on the value attributed to each EMS call. In the literature, it was noted that the minimum cost of an EMS call in 2017 was $\$ \mathrm{C} 499$, the moderate cost was $\$ \mathrm{C} 1626$ and the maximum cost was $\$ \mathrm{C} 2254) .{ }^{13}$ Therefore, due to the reduction of 157.8 EMS calls over the intervention year, the estimated cost avoided during the RCT ranged from $\$ 78742$ to $\$ 355681$. This resulted in a cost offset of \$54-\$243 per resident (see table 5). Under the minimum cost offset assumption, the ICER was $\$ 1133$, and under both the moderate and maximum assumptions, the intervention was dominant (see table 5).

\section{Potential net programme cost to paramedic services}

The range of potential programme costs if communities were to implement the $\mathrm{CP} @$ clinic programme in the future would be expected to vary depending on their staffing model. Table 6 shows the matrix of the potential net cost, from the perspective of the paramedic service, of implementing CP@clinic in two buildings and in four buildings according to each combination of total programme cost and cost offset assumptions. The net potential cost ranges from $-\$ 36259$ (capacity saving) to $\$ 58838$ for two buildings and from $-\$ 90979$ (capacity saving) to $\$ 90716$ for four buildings.

\section{DISCUSSION}

This paper presents a cost-utility analysis of the CP@ clinic programme with several sensitivity analyses. The incremental cost per QALY for CP@clinic is very reasonable compared with existing Canadian literature on CP interventions. The ICER of a home visit programme in Renfrew County, Ontario has been described to be between $\$ 67000$ and $\$ 76000^{8}$ compared with the $\mathrm{CP} @$ 
Table 4 Programme staffing costs in 2016 Canadian dollars

\begin{tabular}{|c|c|c|}
\hline $\begin{array}{l}\text { Total staffing } \\
\text { as implemente } \\
\text { during RCT ( } 5\end{array}$ & $\begin{array}{l}\text { Potential staffing } \\
\text { costs for a future site } \\
\text { with } 2 \text { buildings }\end{array}$ & $\begin{array}{l}\text { Potential staffing } \\
\text { costs for a future } \\
\text { site with } 4 \text { buildings }\end{array}$ \\
\hline
\end{tabular}

Additional paramedic staff*

Number of buildings implementing CP@clinic

13

2

4

Cost of additional paramedic staff per year (50 weeks, hourly salary including benefits ranged from $\$ 50.33$ to $\$ 54.99$ per hour)

- Actual: as implemented during the trial

$\$ 31130$

- Minimum: two paramedics on modified duties

- Moderate: one funded CP, one paramedic on modified duties

- Maximum: two funded CPs
$-\$ 0 \quad \$ 0$

- $\$ 21996 \quad \$ 43992$

$-\quad \$ 43992$

$\$ 87984$

\section{Additional supervision and administration}

Cost of additional supervisory and administrative staff hours per year (50 weeks)

- Actual: as implemented during the trial

$\$ 32522$

- Minimum: 1 hour per week

- $\$ 5499 \quad \$ 5499$

- Moderate: 1.5 hours per week

$-\quad \$ 8249$

$\$ 8249$

- Maximum: 2 hours per week

- $\quad \$ 10998$

$\$ 10998$

\section{Other staffing (programme evaluation, data repository, training development)}

Cost of other staffing ( $\$ 3000 /$ year base cost)

- Actual: as implemented during the trial

$\$ 0$

$-$

in-kind

- Moderate: 50/50 mixed funding model

- Maximum: funded entirely by the paramedic service

Totals

- Actual costs during RCT (five sites) $\$ 63652$

- Minimum assumption scenarios (one site)

- Moderate assumption scenarios (one site)

- Maximum assumption scenarios (one site)

$\begin{array}{lll}- & \$ 5499 & \$ 5499 \\ - & \$ 31745 & \$ 53741 \\ - & \$ 57990 & \$ 101982\end{array}$

*Paramedic staff funded specifically for the community paramedicine role and not on modified duty.

CP, community paramedic; CP@clinic, Community Paramedicine at Clinic programme; RCT, randomised controlled trial.

clinic ICER of $\$ 2933$. The commonly held threshold for willingness to pay for an intervention is $\$ \mathrm{C} 50000{ }^{17}$ The results highlight that through $\mathrm{CP} @$ clinic it is possible to not only reduce the number of EMS calls emanating from subsidised (social) housing buildings, but to improve resident health-related quality of life while doing so. This presents an opportunity for health policy to recommend this programme for upscale, with vast potential benefits beyond those explored within the scope of this evaluation (eg, hospitalisations). Considering this empirical evidence, the argument for adoption of the CP@clinic programme is very strong.

Our sensitivity analyses present different scenarios that can be taken into account when planning an implementation of CP@clinic. Since the programme has fixed implementation costs (eg, laptop) that could be used for running CP@clinic in many buildings without additional investment, the net programme cost for a future site is dependent on the number of buildings in which they will be implementing, as well as the staffing model used. Different assumptions of staffing needed to implement the programme and also the potential cost offset have been presented since, in reality, paramedic service organisations had different local solutions for their implementation of the programme. Though some implemented CP@ clinic with a full staffing complement, others were able to use their staff who were on modified duty. Combinations of regular and modified duty staff were also abundant in reality. Some paramedic services noted that the continuity and consistency provided by having the same staff person was beneficial. However, the economic savings of using modified staff present an opportunity that cannot be ignored in the practical situation of scarce funding and resources to provide healthcare. ${ }^{18} 19$ With this in mind, we would recommend that CP@clinic could ideally be staffed by one funded CP, plus one CP on modified 
Table 5 Cost-utility analysis of community paramedicine at clinic programme. Intervention in 2016 Canadian dollars

$\begin{array}{ll}\text { QALY change per resident } & 0.03 \\ \text { Programme cost per resident for } & \$ 88 \\ \text { full RCT (direct costs and staffing } & \\ \text { of } \$ 128462 \text { for } 1461 \text { units) } & \end{array}$

Base case ICER (programme cost $\$ 2933$ per QALY)

$\begin{aligned} & \text { Probabilistic sensitivity analysis } \\ & \text { using bootstrapping }\end{aligned}$
$\begin{array}{ll}\text { QALY change per resident }(95 \% \mathrm{Cl}) & 0.03(0.01 \text { to } 0.05) \\ \text { Programme cost per resident by } & \$ 35-292 \\ \text { site } & \\ \text { Mean ICER (Fieller's } 95 \% \mathrm{Cl}) & \$ 4850(\$ 2246 \text { to } \\ & \$ 12396)\end{array}$

Analysis including potential cost offset due to EMS call reduction*

Minimum assumption: \$499/EMS

call

Cost offset per resident

ICER (cost per QALY)

Moderate assumption: \$1626/EMS call

Cost offset per resident
ICER (cost per QALY)

(-\$2933) (intervention dominant)

Maximum assumption: \$2254/EMS call

Cost offset per resident
ICER (cost per QALY)

(-\$5167) (intervention dominant)

${ }^{*}$ Reduction of 10.8 EMS calls per 100 residents.

EMS, emergency medical service; ICER, incremental costeffectiveness ratio; QALY, quality-adjusted life year; RCT, randomised controlled trial.

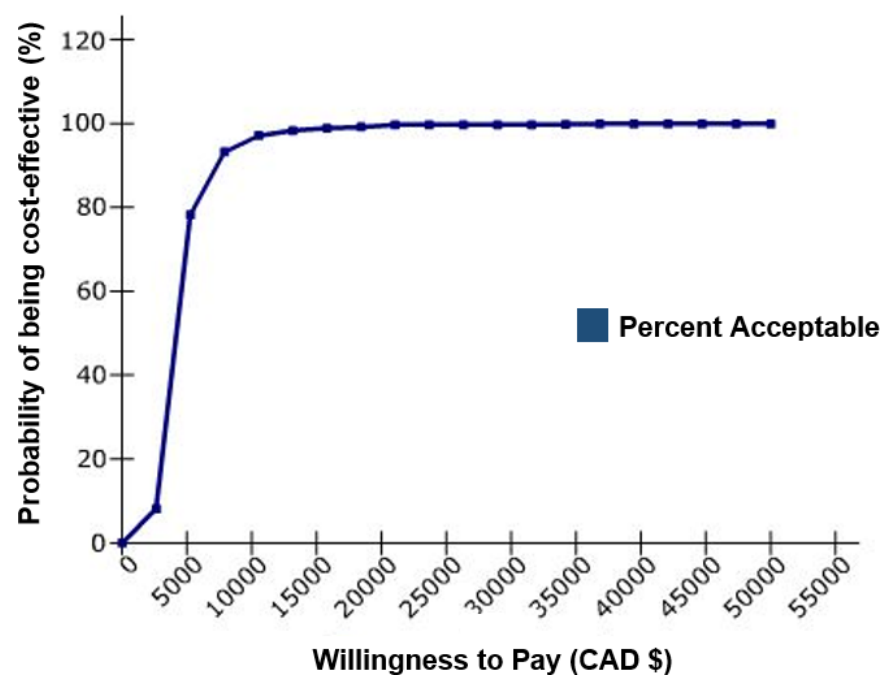

Figure 2 Cost-effectiveness acceptability curve. duties; having one consistent CP would help foster a positive relationship between the $\mathrm{CP} @$ clinic attendee and the paramedic, ${ }^{6}$ and would be more cost-effective than the model using two funded CPs.

Other CP or similar programmes in the literature may not be comparable as they describe substantially different scenarios and contexts. However, they do describe and help with understanding the comparative value of $\mathrm{CP} @$ clinic within the arena of health programming. For example, the cost per participant in a remote patient monitoring (RPM) CP programme in Southern Ontario was estimated at $\$ 1134 .^{20}$ Our cost per resident of $\$ 88$ is very reasonable and much lower than the cost of RPM, which by nature is more labour intensive. If we postulate that we should account for programme attendees only, the cost is slightly more at $\$ 216$ per attendee, which is still much lower than that of the RPM. However, in the case of CP@clinic, the programme is offered for all residents of the subsidised housing buildings therefore, we feel it is appropriate to cost it out as though everyone could attend. The RPM programme has been documented to avoid up to $26 \%$ EMS calls $(\mathrm{n}=453),{ }^{20}$ and with their overall programme cost of $\$ 737100$, the cost per EMS call avoided was $\$ 1627$. In contrast, CP@clinic has also been documented to avoid a comparable proportion of $19 \%$ of EMS calls ( $\mathrm{n}=157.8$ calls), ${ }^{3}$ at a cost per call avoided of \$814, demonstrating that CP@clinic has the ability to be an affordable CP programme.

One of the limitations of this work is that we were unable to account for all loss to follow-up through death and moving of residents, due to information constraints. We have potentially underestimated the impact of the CP@clinic programme on residents' health and healthcare utilisation. We have not formally considered the long-term impacts of the programme on the reduction of morbidity, mortality and hospital admission avoidance. This information requires careful linkage to geographical and individual information in order to be able to piece together the long-term picture and was beyond the scope of this economic evaluation. This has been planned for future analysis. Similarly, it was outside of the scope of this study to track the specific nature of the calls made preintervention and postintervention to be able to assign a specific cost to each call. Thus, sensitivity analyses based on the range of potential call values were conducted. Additionally, we have assumed a consistent programme effect size for all staffing scenarios, but realistically the effect size may have been greater with more paramedic staff on hand. Future research should determine the implications of different staffing models on the scale of intervention effect. We have also only considered the perspective of the paramedic service since in Ontario they determine how to allocate staff and resource funding to extra programmes. The perspective of society or other payers could be considered in future work. 
Table 6 Potential net programme cost for a future paramedic service implementing community paramedicine at clinic programme under different assumption scenarios

\section{Potential programme costs - two intervention buildings (direct costs and staffing)}

\begin{tabular}{ccl}
\hline $\begin{array}{l}\text { Minimum assumption } \\
\text { (\$18461) }\end{array}$ & $\begin{array}{l}\text { Moderate assumption } \\
\text { (\$44707) }\end{array}$ & $\begin{array}{l}\text { Maximum assumption } \\
\mathbf{( \$ 7 0 9 5 2 )}\end{array}$ \\
\hline 6347 & 32593 & 58838 \\
$(-21013)$ & 5233 & 31478 \\
$(-36259)$ & $(-10013)$ & 16232
\end{tabular}

$\begin{array}{llrrr}\begin{array}{l}\text { Potential cost } \\ \text { offsets }^{*}\end{array} & \text { Minimum assumption }(\$ 12114) & 6347 & 32593 & 58838 \\ & \text { Moderate assumption }(\$ 39474) & (-21013) & 5233 & 31478 \\ & \text { Maximum assumption }(\$ 54720) & (-36259) & (-10013) & 16232\end{array}$

\section{Potential programme costs - four intervention buildings (direct costs} and staffing)

\begin{tabular}{llccc} 
& & $\begin{array}{l}\text { Minimum assumption } \\
\mathbf{( \$ 1 8 4 6 )}\end{array}$ & $\begin{array}{l}\text { Moderate assumption } \\
\mathbf{( \$ 6 6 7 0 3 )}\end{array}$ & $\begin{array}{l}\text { Maximum assumption } \\
\mathbf{( \$ 1 1 4 9 4 4 )}\end{array}$ \\
$\begin{array}{l}\text { Potential cost } \\
\text { offsets† }\end{array}$ & Minimum assumption $(\$ 24228)$ & $(-5767)$ & 42475 & 90716 \\
& Moderate assumption $(\$ 78949)$ & $(-60488)$ & $(-12246)$ & 35995 \\
& Maximum assumption $(\$ 109440)$ & $(-90979)$ & $(-42737)$ & 5504 \\
\hline
\end{tabular}

*Expected offset for two future buildings, based on the randomised controlled trial results of 157.8 fewer calls in 13 buildings, and a value of $\$ 499 /$ call for minimum, $\$ 1626 /$ call for moderate and $\$ 2254 /$ call for maximum cost offset assumptions.

†Expected offset for four future buildings, based on the randomised controlled trial results of 157.8 fewer calls in 13 buildings, and a value of $\$ 499 /$ call for minimum, $\$ 1626 /$ call for moderate and $\$ 2254 /$ call for maximum cost offset assumptions.

QALY, quality-adjusted life year.

\section{CONCLUSION}

In summary, CP@clinic not only avoided 157.8 EMS calls, but improved the quality of life of vulnerable older adults living in subsidised housing. Including the reduction in the EMS calls and their associated costs in the analysis resulted in an intervention that is both cheaper and more effective than usual care. All sensitivity analysis for cost per QALY were below commonly held willingness to pay thresholds indicating that $\mathrm{CP} @$ clinic represents value for money.

\section{Author affiliations}

${ }^{1}$ Department of Family Medicine, McMaster University, Hamilton, Ontario, Canada ${ }^{2}$ Department of Health Research Methods, Evidence, and Impact, McMaster University, Hamilton, Ontario, Canada

${ }^{3}$ Biostatistics Unit, St. Joseph's Healthcare Research Institute, Hamilton, Ontario, Canada

${ }^{4}$ Pharmacy Consulting, Health Benefits and Payment Solutions, TELUS Health, Toronto, Ontario, Canada

Contributors GA, RA, MP and FM were involved in study conceptualisation and implementation. RA, GA and MP analysed and interpreted the data, and DO'R and LT provided guidance in the analysis planning and interpretation. All authors were involved in preparing the paper and approved the final manuscript.

Funding This work was supported by the Hamilton Academic Health Sciences Organisation and Canadian Institutes of Health Research under Grant \#133563. The funder had no role in the identification, design, conduct or reporting of the analysis.

Competing interests None declared.

Patient consent for publication Not required.

Ethics approval This study was approved by the Hamilton Integrated Research Ethics Board (\#14-210 and \#14-645).

Provenance and peer review Not commissioned; externally peer reviewed.

Data availability statement Data are available upon reasonable request. The data that support the findings of this study are not publicly available due to them containing information that could compromise participant privacy. Deidentified, limited data will be shared by the corresponding author upon request.
Supplemental material This content has been supplied by the author(s). It has not been vetted by BMJ Publishing Group Limited (BMJ) and may not have been peer-reviewed. Any opinions or recommendations discussed are solely those of the author(s) and are not endorsed by BMJ. BMJ disclaims all liability and responsibility arising from any reliance placed on the content. Where the content includes any translated material, BMJ does not warrant the accuracy and reliability of the translations (including but not limited to local regulations, clinical guidelines, terminology, drug names and drug dosages), and is not responsible for any error and/or omissions arising from translation and adaptation or otherwise.

Open access This is an open access article distributed in accordance with the Creative Commons Attribution Non Commercial (CC BY-NC 4.0) license, which permits others to distribute, remix, adapt, build upon this work non-commercially, and license their derivative works on different terms, provided the original work is properly cited, appropriate credit is given, any changes made indicated, and the use is non-commercial. See: http://creativecommons.org/licenses/by-nc/4.0/.

\section{ORCID iDs}

Gina Agarwal http://orcid.org/0000-0002-5691-4675

Melissa Pirrie http://orcid.org/0000-0003-1407-4775

\section{REFERENCES}

1 Chan J, Griffith LE, Costa AP, et al. Community paramedicine: a systematic review of program descriptions and training. CJEM 2019;21:749-61.

2 Agarwal G, Angeles R, Pirrie M, et al. Evaluation of a community paramedicine health promotion and lifestyle risk assessment program for older adults who live in social housing: a cluster randomized trial. CMAJ 2018;190:E638-47.

3 Agarwal G, Angeles R, Pirrie M, et al. Reducing 9-1-1 emergency medical service calls by implementing a community paramedicine program for vulnerable older adults in public housing in Canada: a multi-site cluster randomized controlled trial. Prehosp Emerg Care 2019;23:718-29.

4 Nixon JB, Ritchie SD, Wenghofer EF, et al. Paramedic perspectives of community paramedicine and quality of work life in northern Ontario, Canada [master's thesis on the internet. Sudbury, ON: Laurentian University, 2019. https://zone.biblio.laurentian.ca/handle/10219/3241

5 Canadian Healthcare Technology. Paramedics to use ultrasound and portable lab tests, 2016. Available: https://www.canhealth.com/ 2016/09/21/paramedics-to-use-ultrasound-and-portable-lab-tests/ [Accessed 6 Aug 2019]. 
6 Brydges M, Denton M, Agarwal G. The CHAP-EMS health promotion program: a qualitative study on participants' views of the role of paramedics. BMC Health Serv Res 2016;16:435.

7 Guo B, Corabian P, Yan C, et al. Community paramedicine: program characteristics and evaluation. Institute of health economics, 2017. Available: https://www.ihe.ca/publications/community-paramedicineprogram-characteristics-and-evaluation [Accessed 2 Jul 2019].

8 Ashton C, Duffie D, Millar J. Conserving quality of life through community paramedics. Healthc Q 2017;20:48-53.

9 Agarwal G, McDonough B, Angeles R, et al. Rationale and methods of a multicentre randomised controlled trial of the effectiveness of a Community Health Assessment Programme with Emergency Medical Services (CHAP-EMS) implemented on residents aged 55 years and older in subsidised seniors' housing buildings in Ontario, Canada. BMJ Open 2015;5:e008110.

10 EQ-5D-3L User Guide. EuroQol research foundation, 2018. Available: https://euroqol.org/publications /user-guides

11 Agarwal G, Habing K, Pirrie M, et al. Assessing health literacy among older adults living in subsidized housing: a cross-sectional study. Can J Public Health 2018;109:401-9.

12 Auditor general of Ontario. Social and affordable housing (Chapter 3). Ontario, CA: Ministry of Housing, 2017: 697-747. http://www.auditor. on.ca/en/content/annualreports/arreports/en17/v1 314en17.pdf

13 Agarwal G, Angeles R, Pirrie M, et al. Effectiveness of a community paramedic-led health assessment and education initiative in a seniors' residence building: the community health assessment program through emergency medical services (CHAP-EMS). BMC Emerg Med 2017;17:8.

14 Statistics Canada. Table 18-10-0004-08 consumer price index, monthly, percentage change, not seasonally adjusted, Canada, provinces, Whitehorse and Yellowknife-health and personal care.

15 Edwards R, Hounsome B, Russell D. QALY calculation alongside randomised controlled trials: from the torch to the traffic light (in Paris, 2004.

16 Xie F, Pullenayegum E, Gaebel K, et al. A time trade-off-derived value set of the EQ-5D-5L for Canada. Med Care 2016;54:98-105.

17 Neumann PJ, Cohen JT, Weinstein MC. Updating cost-effectivenessthe curious resilience of the $\$ 50,000$-per-QALY threshold. $N$ Engl J Med 2014;371:796-7.

18 Canadian Medical Association. Health care transformation in Canada: change that works, care that lasts, 2018. Available: https:// policybase.cma.ca/documents/policypdf/PD10-05.PDF [Accessed 19 Aug 2019].

19 Ontario Ministry of Health. Hallway health care: a system under strain. Ontario Ministry of health and long-term care, 2019. Available: http://www.health.gov.on.ca/en/public/publications/premiers_ council/report.aspx [Accessed 19 Aug 2019].

20 Brohman MK, Green ME, Dixon J, et al. Community paramedicine remote patient monitoring (CPRPM): benefits evaluation lessons learned, 2015/17. Toronto ON: Canadian health infoway, 2018. 